\title{
Herediter hemorajlk telenjektazili bir vakanın, argon plazma koagülasyonu ve destek tedavisi kombinasyonuyla başarılı yönetimi
}

\author{
The success of combination treatment in the management of a patient with hereditary \\ hemorrhagic telangiectasia
}

\author{
Atakan YEŞIL ${ }^{1}$, Ebubekir ŞENATEŞ², Kadir KAYATAŞ ${ }^{3}$, Banu ERKALMA ŞENATEŞ ${ }^{4}$, Alper GÜÇÜTÜRK ${ }^{3}$, \\ Refik DEMIRTUNÇ3 \\ Haydarpaşa Numune Eğitim ve Araștırma Hastanesi, ${ }^{1}$ Gastroenteroloji Kliniği, ${ }^{3}$ 3. Dahiliye Kliniği, Istanbul \\ Dicle Üniversitesi Tip Fakültesi, ${ }^{2}$ Gastroenteroloji Bilim Dal, Diyarbakır \\ Diyarbakır Eğitim ve Araştırma Hastanesi, ${ }^{4}$ Dahiliye Kliniği, Diyarbakır
}

Herediter hemorajik telenjiektazi, otozomal dominant geçişli, birçok klinik bulguyla karakterize, anormal vasküler formasyonla ilişkili nadir gözlenen bir hastalıktır. Biz bu vakada, gastrointestinal sistemin multiple bölgesinde (özofagus, mide korpus ve antrumu, duodenum) anjiodisplazik lezyonlarla seyreden, öyküsünde dört kez geçirilmiş miyokard infarktüsü bulunan, acil servise melena ile başvuran 65 yaşındaki olguya tanı anında yapılan argon plazma koagülasyon ve supportif yaklaşım kombinasyonun tedavi başarısın gözlemledik. Tanı anında uygulanan argon plazma koagülasyon ve bipolar koagülasyon yöntemleri bir çok çalışmada tercih edilen yöntemler olmuştur. Bu nedenle biz bu olgumuzda argon plazma koagülasyon yöntemini ve çalışmalarda etkisi kanıtlanmıș konservatif tedavi kombinasyonunu tercih ettik. Bizim vakamızın argon plazma koagülasyon yöntemiyle beraber destek tedavisine verdiği hızlı cevap argon plazma koagülasyonun herediter hemorajik telenjiektaziye bağlı anjiodisplazik lezyonlarda seçkin tedavi yöntemi olduğu görüşünü desteklemektedir

Anahtar kelimeler: Herediter hemorajik telenjiektazi, anjiodisplazik lezyon, argon plazma koagülasyon

\section{GİRISs}

Herediter hemorajik telenjiektazi (HHT), otozomal dominant geçişli, birçok klinik bulguyla karakterize, anormal vasküler formasyonla ilişkili nadir gözlenen bir hastalıktır (1, 2). Multiorgan tutulumuyla karakterize olan HHT, en sık epistaksisle presente olsa da burun, deri, gastrointestinal sistem, akciğer, karaciğer, beyin tutulumu da görülmektedir (3-5). Çok daha nadir olmakla birlikte pulmoner ve koroner arteriyovenöz malformasyonlar, koroner ektaziler şeklinde kardiyovasküler tutulum belirtilmiştir. Gastrointestinal tutulum kendini aşikar demir eksikliği ve semptomlariyla belli ederken, altta yatan neden mukokütanöz telenjiektazilerdir (6). Gastrointestinal tutulumlu hastalarda tedavinin genel prensibini, kanama kontrolünün sağlanması ve kanama tekrarının önlenmesi oluşturur. Bu nedenle kanama potansiyeli olan her lezyon tedavi edilmelidir.

Tedavi seçenekleri temelde endoskopik ve farmakolojik olarak ikiye ayrılır. Endoskopik yöntemler arasında argon plazma koagülasyon (APC), elektrokoagülasyon, lazer, kriyoterapi ve
Hereditary hemorrhagic telangiectasia (Osler-Weber-Rendu syndrome), a vascular disorder with autosomal dominant transmission, has a variety of clinical manifestations. In this case, we monitored a 65-year-old female who admitted to our hospital with gastrointestinal bleeding. Her history revealed repeated myocardial infarction (4 times). We diagnosed multiple angiodysplastic lesions with endoscopic examination. We evaluated the success of combination treatment with argon plasma coagulation and supportive approach at the time of diagnosis. argon plasma coagulation and bipolar coagulation methods have been reported as the preferred treatments in several studies. Therefore, we preferred the combination of argon plasma coagulation and conservative treatment methods in our case. The rapid healing observed with this treatment supports that combination treatment is effective in angiodysplastic lesions associated with hereditary hemorrhagic telangiectasia.

Keywords: Hereditary hemorrhagic telangiectasia, angiodysplastic lesions, argon plasma coagulation

skleroterapi sayılabilir (7-10). Farmakolojik tedaviler arasında östrojen ve progesteron, oktreotid, danazol, traneksamik asit ve aminokaproik asit denenmiștir (11-16). Endoskopik ve farmakolojik tedavinin başarısız olduğu koşullarda radyolojik (transkateter embolizasyon) ve cerrahi tedavi düşünülmelidir (17). Bütün tedavi seçenekleri içerisinde literatürde ön plana çıkan tedavi yaklaşımı, tanı esnasında yapılan APC ve bipolar elektrokoagülasyon yöntemleridir (18).

Biz bu vakada, gastrointestinal sistemin multiple bölgesinde (özofagus, korpus, antrum, duodenum) anjiodisplazik lezyonlarla seyreden, öyküsünde 4 kez geçirilmiş miyokard infarktüsü (MI) bulunan, acil servise melenayla başvuran 65 yaşındaki olguya tanı anında yapılan APC ve supportif yaklaşım kombinasyonun tedavi başarısını inceledik.

\section{OLGU}

Altmışbeş yaşındaki kadın hasta, yakınları tarafından bilinç 


\begin{tabular}{|lccc}
\hline Tablo 1. Laboratuvar bulguları & & \\
\hline Test Adı & Sonuç & Birim & Referans aralık \\
\hline Hemoglobin & 7.4 & $\mathrm{~g} / \mathrm{dL}$ & $13-17$ \\
Hematokrit & 24.7 & $\%$ & $40-50$ \\
\hline Ortalama eritrosit hacmi & 75.7 & $\mathrm{fL}$ & $80-92$ \\
\hline Lökosit & 4.46 & $\mathrm{~K} / \mathrm{mm}^{3}$ & $4.0-10$ \\
\hline Trombosit & 330 & $\mathrm{~K} / \mathrm{mm}^{3}$ & $150-400$ \\
\hline Kan üre azotu & 35 & $\mathrm{mg} / \mathrm{dL}$ & $<33$ \\
\hline Kreatinin & 1.3 & $\mathrm{mg} / \mathrm{dL}$ & $0.70-1.25$ \\
\hline Ürik asit & 11.6 & $\mathrm{mg} / \mathrm{dL}$ & $<8.4$ \\
\hline Total protein & 6.4 & $\mathrm{~g} / \mathrm{dL}$ & $6.4-8.3$ \\
\hline Albumin & 3.3 & $\mathrm{~g} / \mathrm{dL}$ & $3.0-4.5$ \\
\hline Sodyum & 139 & $\mathrm{mEq} / \mathrm{L}$ & $132-146$ \\
\hline Potasyum & 4.3 & $\mathrm{mEq} / \mathrm{L}$ & $3.7-5.4$ \\
\hline Klorür & 104 & $\mathrm{mEq} / \mathrm{L}$ & $94-110$ \\
\hline Kalsiyum & 9.1 & $\mathrm{mg} / \mathrm{dL}$ & $8.8-10.2$ \\
\hline Fosfor & 2.7 & $\mathrm{mg} / \mathrm{dL}$ & $2.3-4.7$ \\
\hline Alanin aminotransferaz & 13 & $\mathrm{IU} / \mathrm{L}$ & $<37$ \\
\hline Alkalen fosfataz & 10 & $\mathrm{IU} / \mathrm{L}$ & $<42$ \\
\hline Gama glutamil transferaz & 32 & $\mathrm{IU} / \mathrm{L}$ & $<64$ \\
\hline
\end{tabular}

bulanıklığı ve melena yakınması nedeni ile acil polikliniğimize getirilmiş. Acilde yapılan fizik muayenesinde hasta sorulan sorulara yanıt vermiyor, bilinç konfüze, oryantasyonu ve kooperasyonu kıstllydı. Tansiyon arteriyeli $135 / 75 \mathrm{mmHg}$, nabız 85 atım/dak, ateş $36.7^{\circ} \mathrm{C}$, solunum sayısı 16/dak saptandı. Baş boyun muayenesinde, alt dudak mukozasında telenjiektazi, cilt soluk, pupiller izokorik ve bilateral direkt ve indirekt pupil refleksleri bilateral alınıyordu. Solunum sistemi muayenesinde akciğer bazallerinde solunum sesleri azalmış ve crackle alınıyordu. Kardiyolojik değerlendirme için yapılan elektrokardiyografide de prekordial Q dalgalanı ve T dalga negatifliği saptandı. Ekokardiyografi yapılan hastada anteroseptum duvarda ağır hipokinezi tespit edildi. Nörolojik değerlendirme için yapılan kraniyal difüzyon magnetik rezonans görüntülemede ve kraniyal tomografide akut nöropatolojiye rastlanmadı. Rektal tuşesinde melena pozitifti. Özgeçmişinde koroner arter hastalığ ilki olarak 8 yl önce ve en son 4 yl önce olmak üzere toplamda 4 kez geçirilmiş miyokard infarktüsü ve 2 adet koroner arter stenti mevcuttu. Hastanın hastaneye ilk başvurusundaki biyokimya değerleri Tablo l'de verilmiştir.

Hasta; üst gastrointestinal sistem kanaması nedeniyle dahiliye kliniğine yatırıldı. Hastanın yapılan gastroskopisinde özofagus, korpus, antrum ve duodenumda çok sayıda anjiodisplazik alanlar izlendi (Resim 1,A-C); tüm bu bölgedeki lezyonlara APC uygulandıktan sonra hastaya eritrosit süspansiyonu transfüzyonu yapıldı. APC ve transfüzyondan sonra yapılan kan sayıminda hemoglobin (9.5 mg/dL) hematokrit (\%29.8) değerlerinin artmasıyla hastanın fizik muayenesinde bilincinin dramatik olarak düzeldiği, koopere olup yer-zaman-ki-
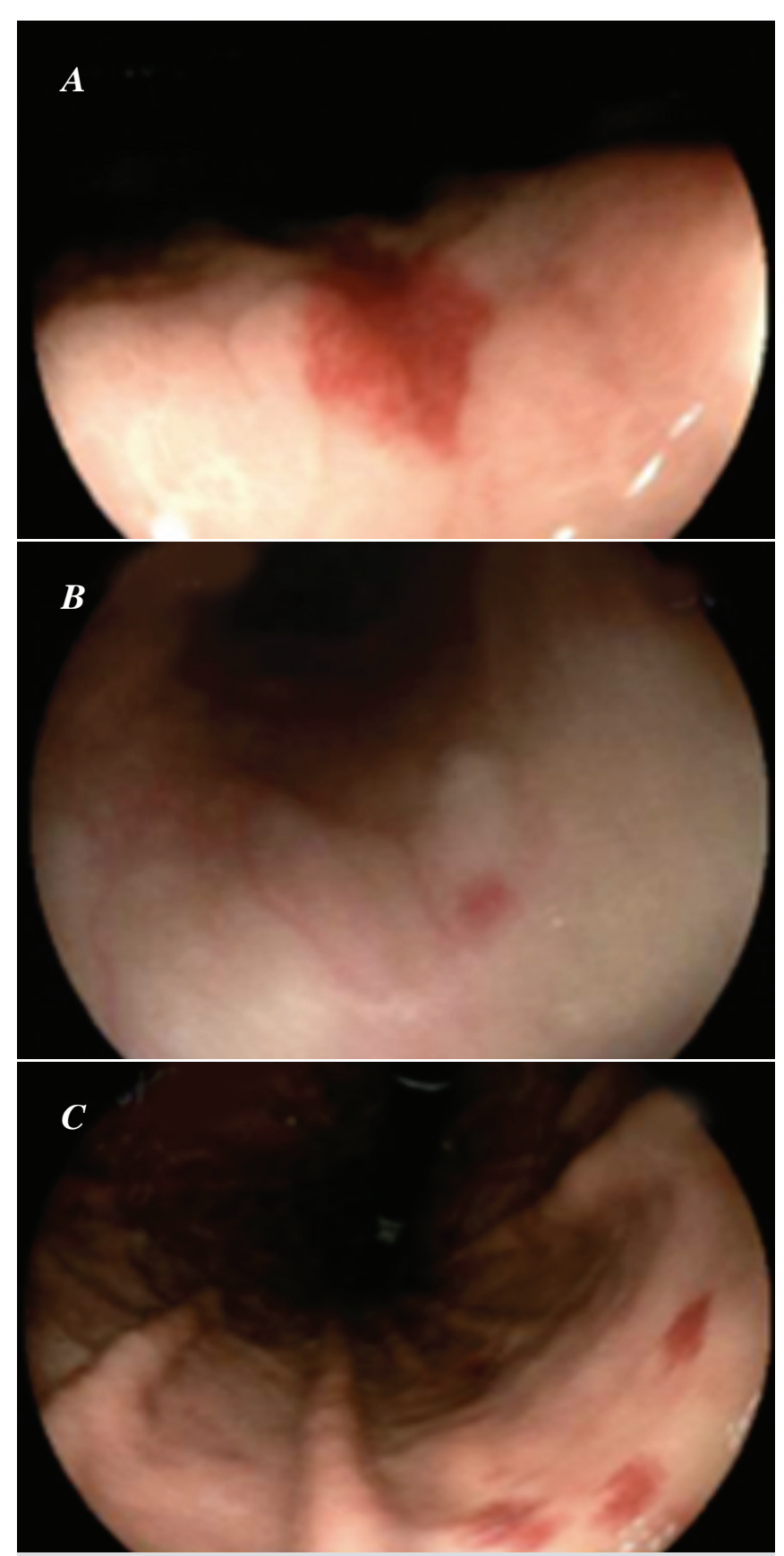

Resim 1; A-C. Hastanın başvuru anında yapılan endoskopisindeki özofagus, korpus, antrum ve duodenumdaki anjiodisplazik alanlar.

şi oryantasyonun tam olduğu izlendi. 10 gün sonra yapılan kontrol endoskopisinde APC yapılan lezyonların iyileştiği izlendi.

\section{TARTISMA}

Bu vakada, multiple anjiodisplazik lezyonlarla seyreden, daha önce defalarca MI öyküsü olan, melana ve şuur bulanıklğ̆ olan 65 yaşındaki kadın hastayı irdeledik.

HHT tanılı hastalarda aneminin en sik nedeni epistaksisle beraber gastrointestinal anjiodisplastik lezyonlardır $(19,20)$. 
Bu nedenle melanayla acile başvuran hastalarda ayırıcı tanıda HHT tanısı da düşünülmelidir. Her ne kadar bu vakada gastroskopiyle anjiodisplastik lezyonların tanısı kolaylıkla konmus olsa da her vakada bu kadar şansh olunmayabilir. Özellikle duodenumun 2. kitasindan sonra ve jejenumda olan lezyonların tanısını koymak daha zordur. Bu olgularda tercih edilen yöntem çift balon enteroskopiyle beraber APC işlemi olabilir (21). Geçmişte yapılan çalışmalarda farmakolojik tedavinin endoskopik tedaviye olan üstünlügü incelenmiştir. Bu amaçla kullanılan ilk ajanlar seksüel hormonlar (östrojen ve progesteron) olmuştur. Her ne kadar Lewis ve arkadaşları (11) bu ilaçların kanama zamanını kısalttığını öne sürseler de daha sonra yayınlanan geniş serili çalışmalarda, HHT'li hastalarda östrojen ve progesteron kullanımının başarısız olduğu bildirilmiştir (12,13). Ayrıca bilinen ciddi yan etkileri de bu ajanların kullanımını ciddi biçimde kısıtlamıştır. Buna ek olarak; hasta sayısının az olduğu, birkaç çalışmada okretoid kullanımının (özellikle uzun etkili formüllerinin), HHT'ye bağlı kanama kontrolünde etkili olduğu gösterilmiştir (14-16). Ancak bu ajanların maliyetinin yüksek olması bu tedavinin geniş kullanım alanı bulmasını engellemiştir.

Tanı anında uygulanan APC ve bipolar koagülasyon yöntemleri bir çok çalışmada tercih edilen yöntemler olmuştur $(17,18)$.

\section{KAYNAKLAR}

1. Govani FS, Shovlin CL. Hereditary haemorrhagic telangiectasia a clinical and scientific review. Eur J Hum Genet 2009;17:860-71.

2. Shovlin CL. Hereditary haemorrhagic telangiectasia:pathophysiology, diagnosis and treatment. Blood Rev 2010;24:203-19.

3. Fiorella ML, Lillo L, Fiorella R. Diode laser in the treatment of epistaxis in patients with hereditary haemorrhagic telangiectasia. Acta Otorhinolaryngol Ital 2012;32:164-9.

4. Candelli M, Pompili M, Suppressa P, et al. Liver involvement in hereditary hemorrhagic telangiectasia: can breath test unmask impaired hepatic firstpass effect? Intern Emerg Med 2012;7:323-9.

5. Olitsky SE. Hereditary hemorrhagic telangiectasia: diagnosis and management. Am Fam Physician 2010;82:785-90.

6. Hsi DH, Ryan GF, Hellems SO, et al. Large aneurysms of the ascending aorta and major coronary arteries in a patient with hereditary hemorrhagic telangiectasia. Mayo Clin Proc 2003;78:774-6.

7. Zarrabeitia R, Albiñana $\mathrm{V}$, Salcedo $\mathrm{M}$, et al. A review on clinical management and pharmacological therapy on hereditary haemorrhagic telangiectasia (HHT). Curr Vasc Pharmacol 2010;8:473-81.

8. Johnston CM, Schoenfeld LP, Mysore JV, Dubois A. Endoscopic spray cryotherapy: a new technique for mucosal ablation in the esophagus. Gastrointest Endosc 1999;50:86-92.

9. Pavey DA, Craig PI. Endoscopic therapy for upper-GI vascular ectasias. Gastrointest Endosc 2004;59:233-8.

10. Kantsevoy SV, Cruz-Correa MR, Vaughn CA, et al. Endoscopic cryotherapy for the treatment of bleeding mucosal vascular lesions of the GI tract: a pilot study. Gastrointest Endosc 2003;57:403-6.

11. Lewis BS, Salomon P, Rivera-MacMurray S, et al. Does hormonal therapy have any benefit for bleeding angiodysplasia? J Clin Gastroentero 1992;15:99-103.

12. Barkin JS, Ross BS. Medical therapy for chronic gastrointestinal bleeding of obscure origin. Am J Gastroenterol 1998;93:1250-4.

13. Hodgson H. Hormonal therapy for gastrointestinal angiodysplasia. Lancet 2002;359:1630-1.

14. Plessevaux H, Coremans G, Rutgeert P, et al. Octreotide in the treatment of bleeding gastrointestinal vascular malformations. Gastroenterology 1996;110:A353.
Bu nedenle biz bu olgumuzda APC yöntemini ve çalışmalarda etkisi kanıtlanmış konservatif tedavi kombinasyonunu tercih ettik. Bizim vakamızın APC yöntemiyle beraber destek tedavisine verdiği hızlı cevap APC'nin HHT'ye bağlı anjiodisplazik lezyonlarda seçkin tedavi yöntemi olduğu görüşünü desteklemektedir (22-24). Yapılan yayınları incelediğimizde HHT'li olgularda özellikle endoskopik ve farmakolojik tedavi kombinasyonun uygulandığı prospektif bir çalışmanın olmaması bu alandaki bilgilerimizi sinırlamaktadır. Bu nedenle kombinasyon tedavisini içeren geniş serili çalışmalara ihtiyaç vardır. Ayrıca HHT birçok sistemi etkilediği gibi kardiyovasküler sistemde de çeşitli lezyonlara neden olur. En sık pulmoner arteriyovenöz malformasyon olmak üzere, koroner arteriyovenöz malformasyon, koroner ektaziye neden olabilir.Yine çok nadir olarak, normal koroner arterle birlikte bile miyokard infarktüsü bile rapor edilmiştir $(25,26)$. Bizim vakamızda hastanın ilk koroner olay geçirdiğindeki yaşını ve diyabetes mellitus, hiperlipidemi gibi önemli risk faktörlerinin yokluğunu düşündügümüzde; beklenenden sık ve yaygın koroner arter hastalığ görülmektedir. HHT'nin endotelyal disfonksiyonla komplike olabileceği, hatta bunun kanıtlanması için asetilkolin testlerinin yapılabileceği düşünülmektedir (27). Bu bilgiler ışı̆̆ında HHT'li olgu sayısının yüksek olduğu geniş serili prospektif randomize çalışmalara ihtiyaç olduğu gerçeği açıktır.

15. Orsi P, Guatti-Zuliani C, Okolicsanyi L. Long-acting octreotide is effective in controlling rebleeding angiodysplasia of the gastrointestinal tract. Dig Liver Dis 2001;33:330-4.

16. Nardone G, Rocco A, Balzano T, Budillon G. The efficacy of octreotide therapy in chronic bleeding due to vascular abnormalities of the gastrointestinal tract. Aliment Pharmacol Ther 1999;13:1429-36.

17. Takasu S, Sakurai Y. Vascular ectasia (angiodysplasia). Nihon Naika Gakkai Zasshi 1994;83:1266-70

18. Jensen D, Jutabha R, Kovacs T, et al. A randomized prospective study of endoscopic hemostasis with argon plasma coagulator compared to Gold Probe for bleeding GI angiomas. Gastrointest Endosc 1999;49:AB167.

19. Ragsdale JA. Hereditary hemorrhagic telangiectasia: from epistaxis to lifethreatening GI bleeding. Gastroenterol Nurs 2007;30:293-9.

20. Gordon FH, Watkinson A, Hodgson H. Vascular malformations of the gastrointestinal tract. Best Pract Res Clin Gastroenterol 2001;15:41-58.

21. Foutch PG, Sawyer R, Sanowski RA. Push-enteroscopy for diagnosis of patients with gastrointestinal bleeding of obscure origin. Gastrointest Endosc 1990;36:337-41

22. Kwan V, Bourke MJ, Williams SJ, et al. Argon plasma coagulation in the management of symptomatic gastrointestinal vascular lesions: experience in 100 consecutive patients with long-term follow-up. Am J Gastroenterol 2006;101:58-63.

23. Olmos JA, Marcolongo M, Pogorelsky V, et al. Argon plasma coagulation for prevention of recurrent bleeding from GI angiodysplasias. Gastrointest Endosc 2004;60:881-6.

24. Olmos JA, Marcolongo M, Pogorelsky V, et al. Long-term outcome of argon plasma ablation therapy for bleeding in 100 consecutive patients with colonic angiodysplasia. Dis Colon Rectum 2006;49:1507-16.

25. Kurnik PB, Heymann WR. Coronary artery ectasia associated with hereditary hemorrhagic telangiectasia. Arch Intern Med 1989;149:2357-9.

26. Tsuiki K, Tamada Y, Yasui S. Coronary artery aneurysm without stenosis in association with Osler-Weber-Rendu disease-a case report. Angiology 1991;42:55-8.

27. Bugiardini R, Bairey Merz CN. Angina with 'normal' coronary arteries: a changing philosophy. JAMA 2005;293:477-84. 